\title{
Synergistic protective effects of escin and low-dose glucocorticoids against vascular endothelial growth factor-induced blood-retinal barrier breakdown in retinal pigment epithelial and umbilical vein endothelial cells
}

\author{
FENGLAN ZHANG，XUEJING MAN，HUAJUN YU，LIMEI LIU and YUANBIN LI \\ Department of Ophthalmology, Yantai Yuhuangding Hospital, Yantai, Shandong 264001, P.R. China
}

Received January 21, 2014; Accepted October 1, 2014

DOI: $10.3892 / \mathrm{mmr} .2014 .2833$

\begin{abstract}
Previous studies have shown that escin possesses glucocorticoid (GC)-like anti-edematous and anti-inflammatory effects. The present study was designed to investigate whether escin exhibits synergistic protective effects against blood-retinal barrier (BRB) breakdown when combined with $\mathrm{GC}$ in an in vitro monolayer BRB model, based on retinal pigment epithelial (RPE) cells and human umbilical vein endothelial cells (HUVECs). The results showed that low concentrations of escin and triamcinolone acetonide (TA) administered separately did not affect BRB trans-endothelial (epithelium) resistance (TEER). However, when administered together, escin and TA significantly inhibited reduced BRB TEER following treatment with vascular endothelial growth factor (VEGF). Furthermore, low-concentrations of escin and TA administered together significantly increased the expression levels of occludin and ZO-1. This demonstrates that escin and GC have synergistic protective effects against BRB breakdown, and the molecular mechanisms may be related to the upregulation of occludin and ZO-1 expression. The combination of escin with GC indicates a potential beneficial strategy for the treatment of breakdown of the BRB.
\end{abstract}

\section{Introduction}

Breakdown of the blood-retinal barrier (BRB) is an early event in the pathogenesis of diabetic retinopathy (DR) (1). One consequence of BRB breakdown in diabetics is the accumulation of plasma protein and osmotically obliged fluid in the

Correspondence to: Dr Fenglan Zhang or Mrs. Yuanbin Li, Department of Ophthalmology, Yantai Yuhuangding Hospital, 20 Yu Huangding East Road, Yantai, Shandong 264001, P.R. China E-mail: zhangfenglan21st@126.com

E-mail: yuanbinli@yeah.net

Key words: escin, blood-retinal barrier, vascular endothelial growth factor, glucocorticoids, occludin, ZO-1, retinal pigment epithelial cell, umbilical vein endothelial cell neural interstitium. This causes pathological retinal swelling, neuronal disorganization and vision loss.

Vascular endothelial growth factor (VEGF), one of the vascular permeability factors, mediates increased vascular permeability and colocalizes with extravasated albumin in major retinal diseases such as DR $(2,3)$. Increased levels of VEGF have been shown to induce a reduction in the expression levels of occludin and ZO-1, two important junctional proteins that are expressed in vascular endothelial junctional complexes, thereby leading to increased tissue permeability (4).

Glucocorticoids (GCs) have been shown experimentally to reduce the breakdown of the BRB by directly affecting the endothelial cells through regulating the phosphorylation, organization and content of tight junction proteins (5). It has been reported that triamcinolone acetonide (TA) can upregulate the expression of the tight junction transmembrane protein occludin in animals (6). Although GCs have been shown to ameliorate macular edema, the side effects accompanying treatment make their frequent use problematic. One of the major side effects of intravitreal injection of TA is a steroid-induced increase in intraocular pressure (IOP). One study demonstrated that a rise in IOP to values higher than $21 \mathrm{mmHg}$ is expected to occur in $\sim 50 \%$ of the eyes treated (7). The frequency of cataract surgery following intravitreal injection of high-concentration TA in elderly patients is increasing (8).

Escin is a natural mixture of triterpene saponins, which mainly consists of A, B, C and D escin (Fig. 1). Previous studies have indicated that escin exerts anti-inflammatory and anti-edematous effects $(9,10)$. Escin has been reported to be a safe and potent anti-inflammatory agent with a long-lasting, effective anti-inflammatory action without immunosuppression $(11,12)$. It also exerts synergistic anti-inflammatory effects with low doses of GCs in vivo and in vitro (13). In China, escin is widely used clinically for the treatment of retinal vein occlusion and central serous chorioretinopathy (14-16).

The current study was designed to investigate whether a combination of escin and GCs could produce synergistic protective effects against BRB breakdown in retinal pigment epithelial (RPE) cells and human umbilical vein endothelial cells (HUVECs). 


\section{Materials and methods}

Drugs and cells. Sodium aescinate, for injection with escin, was obtained from Shandong Luye Pharmaceutical Company Limited (batch no.: 1212024; Yantai, China). Triamcinolone acetonid (batch no.: SLBB0079V; Sigma-Aldrich, St. Louis, MO, USA) was dissolved in 100\% dimethyl sulfoxide (DMSO; Sigma-Aldrich) and diluted with DMSO and the appropriate cell culture medium to the desired concentration, with a final DMSO concentration of $0.1 \%$ for in vitro studies. DMSO was added to cultures at $0.1 \%(\mathrm{v} / \mathrm{v})$ as a solvent control. ARPE-19 human RPE cell cultures, were obtained from the Shandong Eye Institute (Qingdao, China). HUVECs were obtained from Shandong Luye Pharmaceutical Company Limited (Yantai, China). Limited Dulbecco's modified Eagle medium (DMEM; Gibco-BRL, Carlsbad, CA, USA) supplemented with $10 \%$ fetal calf serum (FCS; Gibco-BRL) and 1\% penicillin/streptomycin (Beyotime Institute of Biotechnology, Haimen, China) was used as the cell culture medium. Cells were cultured in a humidified atmosphere of $5 \% \mathrm{CO}_{2}$ in air at $37^{\circ} \mathrm{C}$.

Cell culture. ARPE-19 cells and HUVECs were cultured in $5 \mathrm{ml}$ complete medium dishes. When the culture reached $90 \%$ confluence, usually after $\sim 4-5$ days, cells were washed twice with sterile D-Hank's solution (Beyotime Institute of Biotechnology) and separated by short trypsinization (0.05\% trypsin-EDTA; Invitrogen, Carlsbad, CA, USA). The remaining trypsin-EDTA was removed, the tubes were gently shaken until cells were completely ablated and then supplemented with complete DMEM. The pellet was agitated with a pipette. Cells were transferred to three culture bottles and incubated for all experiments.

MTT assay. HUVECs $(100 \mu \mathrm{l})$ and ARPE-19 (100 $\mu \mathrm{l})$ cells were seeded into 96 -well plates at a density of $4 \times 10^{4}$ cells per well. The cells were seeded on the bottom side of the well and cultured in complete DMEM at $37^{\circ} \mathrm{C}$ in $5 \% \mathrm{CO}_{2}$ for $24 \mathrm{~h}$. To investigate the effects of different concentrations of escin and TA on the viability of HUVECs and ARPE-19 cells, following the $24-\mathrm{h}$ culture, the cells were treated with escin at final concentrations of 1.25, 2.5, 5, 10, 20 and $40 \mu \mathrm{g} / \mathrm{ml}$ for another $24 \mathrm{~h}$. TA was added to each well at final concentrations of $0.3125,0.625,1.25,2.5,5$ and $10 \mu \mathrm{mol} / 1$ for another $24 \mathrm{~h}$. The controls were maintained in complete culture without penicillin/streptomycin for the same time period. Following treatment with TA the MTT assay was carried out. In short, the medium was removed, the cells were washed with phosphate-buffered saline (PBS), and $150 \mu$ l MTT solution $(5 \mathrm{mg} / \mathrm{ml})$ was added to each well. ARPE-19 cells and HUVECs were incubated at $37^{\circ} \mathrm{C}$ for $4 \mathrm{~h}$. The medium was removed and the solution aspirated. The resulting formazan crystals were dissolved in $150 \mu \mathrm{l}$ DMSO per well. Absorption was measured with a scanning multi-well spectrophotometer (SpectraMax M3; Molecular Devices, Sunnyvale, CA, USA) at a wavelength of $570 \mathrm{~nm}$. The results are expressed as the mean of the percentage of proliferation, with the control set as $100 \%$ proliferation.

Tight junction building. DMEM was added into a 24-well plate with Transwell inserts (diameter $6.5 \mathrm{~mm}$, pore size

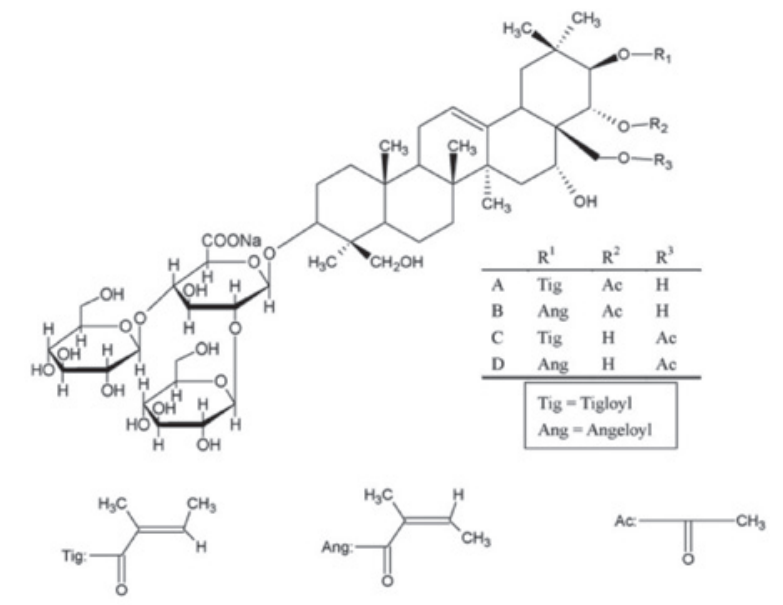

Figure 1. Structure of escin.

$0.45 \mu \mathrm{m}$; Corning Costar, Canton, MA, USA). HUVECs and ARPE-19 cells $\left(4 \times 10^{4}\right.$ cells per transwell insert) in a volume of $100 \mu \mathrm{l}$ were seeded on the bottom side of the insert. The medium was changed every two days. Under these conditions, the formation of tight junctions between cells was detected using the cell resistance meter (Millicell-ERS; Millipor, Billerica, MA, USA). The barrier properties were assessed by daily TEER measurements. TEER was not stable until 2-3 weeks and in vitro BRB models were established. Measurements were performed at $37^{\circ} \mathrm{C}$ and are expressed as relative values after subtracting TEER values from the inserts without cells.

Permeability analysis. Once cell tight junctions had been established, $2 \mu 1$ recombinant human (rh)VEGF (batch no: F0311; Santa Cruz Biotechnology, Santa Cruz, CA, USA) was added (final concentration: ARPE-19 cells $10 \mathrm{ng} / \mathrm{ml}$; HUVECs $100 \mathrm{ng} / \mathrm{ml})$ along with escin $(0.1,1$ or $10 \mu \mathrm{g} / \mathrm{ml}$ ), TA $(0.01,0.1$, or $1 \mu \mathrm{mol} / \mathrm{l})$ or TA combined with escin. Each concentration was added to three parallel wells. The blank control was kept in complete culture except for rhVEGF and antibiotics. At $12 \mathrm{~h}$, the effects of the agents on the cell tight junctions were detected by the cell resistance meter.

Protein extraction and western blotting. HUVECs $(200 \mu \mathrm{l}$; $8 \times 10^{5}$ cells per transwell insert) were added to each well. The HUVECs in 30-mm tissue culture dishes were incubated in a humidified atmosphere of $5 \% \mathrm{CO}_{2}$ in air at $37^{\circ} \mathrm{C}$ for 7 days. After 7 days, cells were stimulated with rhVEGF (VEGF). HUVECs were randomly divided into control, VEGF (100 $\mathrm{ng} / \mathrm{ml}), \mathrm{VEGF}+\mathrm{TA}(0.01 \mu \mathrm{mol} / \mathrm{L}), \mathrm{VEGF}+\operatorname{escin}(0.1 \mu \mathrm{g} / \mathrm{ml})$ and VEGF+ TA $(0.01 \mu \mathrm{mol} / \mathrm{L})+$ escin $(0.1 \mu \mathrm{g} / \mathrm{ml})$ groups. HUVECs were incubated in air at $37^{\circ} \mathrm{C}$ for $12 \mathrm{~h}$. Following incubation the HUVECs were homogenized on ice in cold lysis buffer (Beyotime Institute of Biotechnology) plus 1:100 volume of phenylmethyl sulfonylfluoride. The homogenates were centrifuged at $14,000 \mathrm{x}$ for $5 \mathrm{~min}$ at $4^{\circ} \mathrm{C}$. The supernatants were aliquoted and stored at $-80^{\circ} \mathrm{C}$ following the removal of a small aliquot for protein estimation. Protein concentrations were determined using a bicinchoninic acid (BCA) 
A

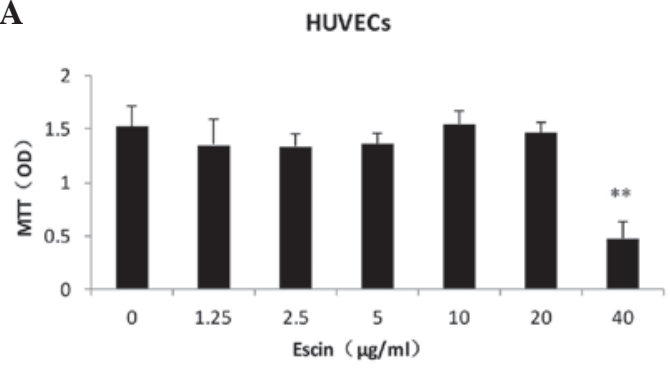

C

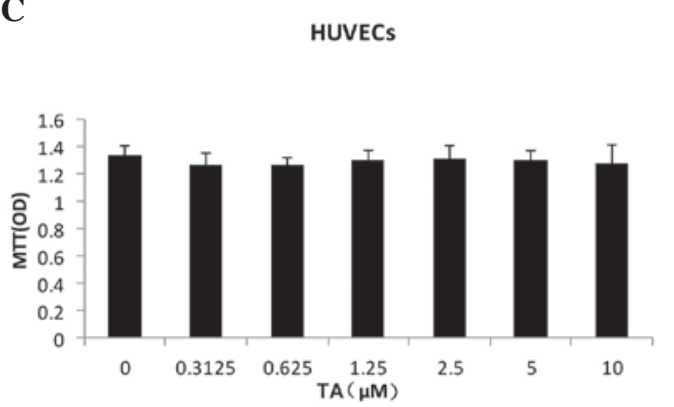

B

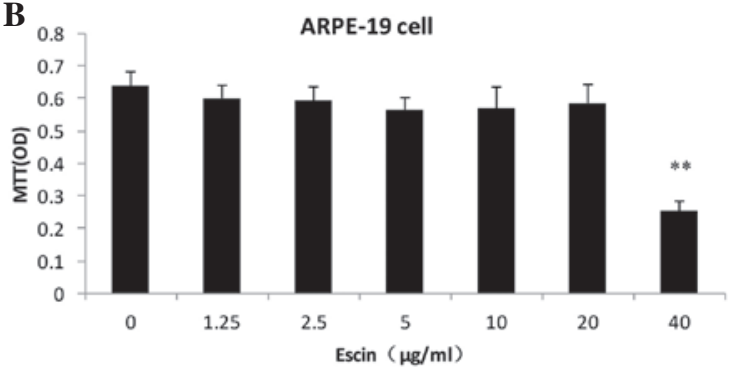

D

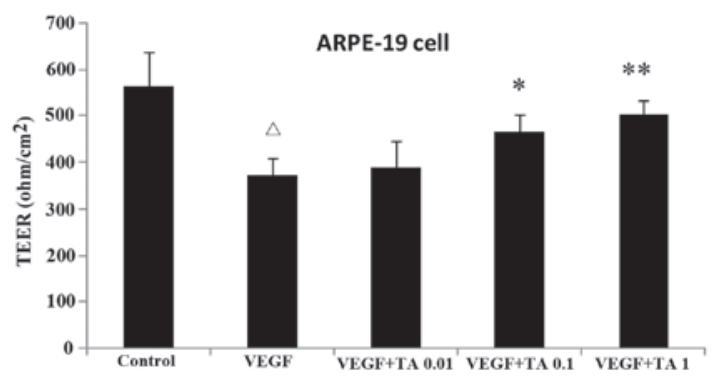

Figure 2. Effect of different concentrations of escin and TA on the viability of HUVECs and retinal pigment epithelial cells (ARPE-19). The MTT assay showed no significant decrease in cellular viability in the (A) HUVEC and (B) ARPE-19 cell cultures following $24 \mathrm{~h}$ of exposure to escin at concentrations between 1.25 and $20 \mu \mathrm{g} / \mathrm{ml}$, or following $24 \mathrm{~h}$ of exposure to TA at all concentrations between 0.3125 and $10 \mu \mathrm{M}$ in (C) HUVECs and (D) ARPE-19 cells. Data are expressed as the mean \pm standard deviation, $n=5$ per group. ${ }^{*} \mathrm{P}<0.01$ vs. the control group. TA, triamcinolone acetonide; HUVEC, human umbilical vein endothelial cells; VEGF, vascular endothelial growth factor; OD, optical density; TEER, transepithelial electrical resistance.

Protein Assay kit (Beyotime). The samples were thawed on ice, mixed with $4 \mathrm{X}$ sample buffer (Invitrogen) and heated at $100^{\circ} \mathrm{C}$ for $5 \mathrm{~min}$. Equivalent amounts of proteins $(50 \mu \mathrm{g})$ were loaded onto $12 \%$ Tris-glycine, SDS-polyacrylamide gels for fractionation at $160 \mathrm{~V}$. Predetermined molecular weight standards (Beyotime Institute of Biotechnology) were used as markers. Proteins on the gel were blotted onto nitrocellulose membranes (Beyotime Institute of Biotechnology) at $106 \mathrm{~V}$ for $70 \mathrm{~min}$ at $4^{\circ} \mathrm{C}$. Following transfer, the membranes were incubated with a blocking buffer $(5 \%$ skim milk in a washing buffer) for $2 \mathrm{~h}$ at room temperature and washed three times (5 min/wash) with $0.1 \%$ Tween 20 in Tris-buffered saline (TBST). Incubation with occludin (cat.no ab31721), ZO-1 (cat.no. ab59720) or GC receptor (cat.no. ab3578) antibodies (all supplied by Abcam, Cambridge, MA, USA) in diluent buffer ( $5 \%$ bovine serum albumin (Beyotime Institute of Biotechnology) and $0.1 \%$ TBST) was performed overnight at $4{ }^{\circ} \mathrm{C}$ (1:1000 dilution). The membrane was subsequently washed three times ( 5 min per wash) with TBST. The primary antibody was probed with horseradish peroxidase-conjugated IgG secondary antibody (1:2000) for $2 \mathrm{~h}$, washed three times in TBST and processed with enhanced chemiluminescence detection reagents (Beyotime). The processed membrane was exposed to photographic films for visualization of the signal. A $\beta$-actin western blot was performed for each membrane as an internal protein loading control.

Evaluation of drug interactions. The interaction between escin and TA was analyzed using the Berenbaum method to determine whether the combination was synergistic. The method is performed based on the following equation: $\mathrm{E}(\mathrm{da}, \mathrm{db})<\mathrm{E}(\mathrm{da})+\mathrm{E}(\mathrm{db})$, where $\mathrm{E}$ is the observed effect, da and $\mathrm{db}$ are the doses of agents a and b. Synergism is indicated when the total effect of a combination is greater than expected from the sum of its effects (17).

Statistical analysis. Quantitative data from the experiments are expressed as the mean \pm standard deviation, significance was determined by one-way analysis of variance followed by Tukey's test. In all cases, $\mathrm{P}<0.05$ was considered to indicate a statistically significant difference.

\section{Results}

Effects of escin and TA on the HUVECs and ARPE-19 cells survival rate. The results of the viability testing showed that escin at a final concentration of $<20 \mu \mathrm{g} / \mathrm{ml}$ had no effect on the cell viability of either cell line and was chosen for all further experiments regarding tissue permeability, junctional protein, and receptor expression. All experimental concentrations of TA had no effects the cell viability of the two cell lines (Fig. 2).

Effects of escin and TA on TEER of the HUVECs and ARPE-19 cells. The TEER of cellular tight junctions in the VEGF group was significantly lower than that of control group $(\mathrm{P}<0.05)$. Escin $(1,10 \mu \mathrm{g} / \mathrm{ml})$ and TA $(0.1,1 \mu \mathrm{mol} / \mathrm{l})$ significantly increased the reduced TEER in cells stimulated with VEGF compared with that in the VEGF-treated control cells $(\mathrm{P}<0.05$ or $\mathrm{P}<0.01)$ (Fig. 3). Escin $(0.1 \mu \mathrm{g} / \mathrm{ml})$ and TA $(0.01 \mu \mathrm{mol} / \mathrm{L})$ administered separately had no significant impact on the TEER of cellular tight junctions, however, administered together they significantly increased the TEER of cellular tight junctions in the presence of VEGF $(\mathrm{P}<0.05)$ (Fig. 4). 
A

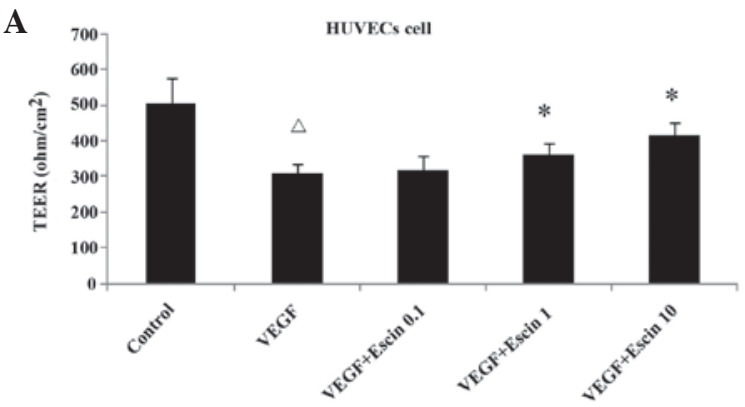

c

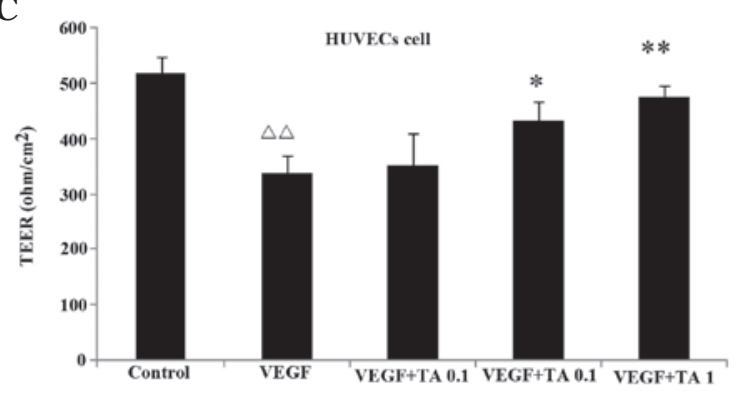

B

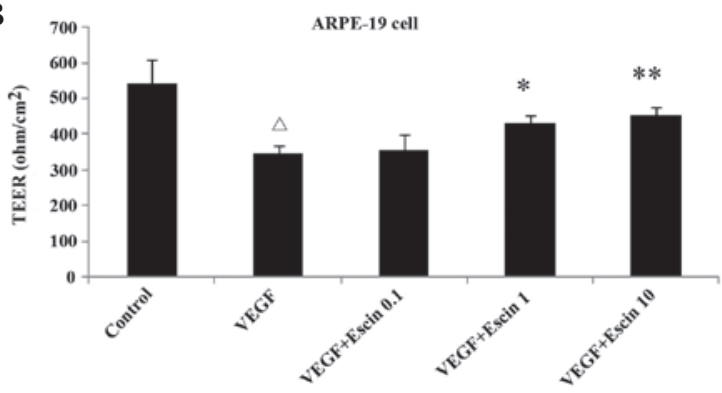

D

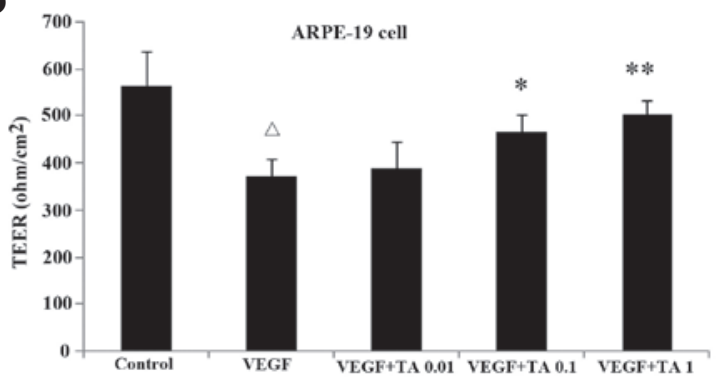

Figure 3. TEER at different concentrations of escin and TA following vascular endothelial growth factor treatment in HUVECs and retinal pigment epithelial (ARPE-19) cells. The TEER of cellular tight junctions in the VEGF group was significantly lower than that of control group (P<0.05). (A and B) Escin $(1,10 \mu \mathrm{g} / \mathrm{ml})$ and $(\mathrm{C}$ and D) TA $(0.1,1 \mu \mathrm{mol} / \mathrm{l})$ significantly increased the reduced TEER in cells stimulated with VEGF compared with that in the VEGF-treated control cells $(\mathrm{P}<0.05$ or $\mathrm{P}<0.01)$. TEER values $\left(\Omega / \mathrm{cm}^{2}\right)$ of different groups are expressed as the mean \pm standard deviation following subtraction of the mean value obtained with inserts without cells. $\mathrm{N}=3$ per group. ${ }^{\Delta} \mathrm{P}<0.05$ and ${ }^{\Delta \Delta} \mathrm{P}<0.01$, vs. the control group. ${ }^{*} \mathrm{P}<0.05$ and ${ }^{* *} \mathrm{P}<0.01$, vs. the $\mathrm{VEGF}$ group. HUVECs, human umbilical vein endothelial cells; TEER, transepithelial electrical resistance; VEGF, vascular endothelial growth factor; TA, triamcinolone acetonide.

A

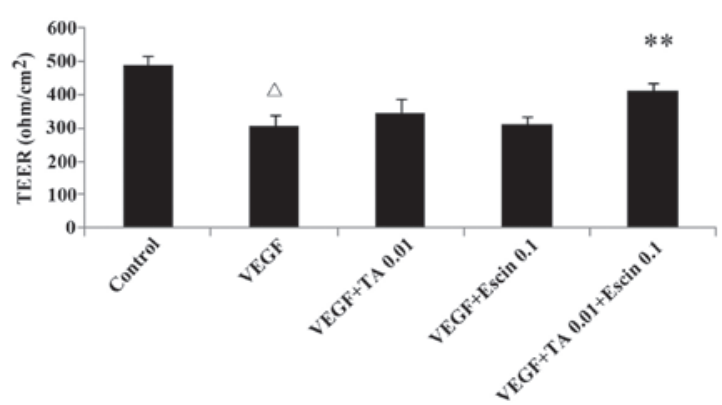

B

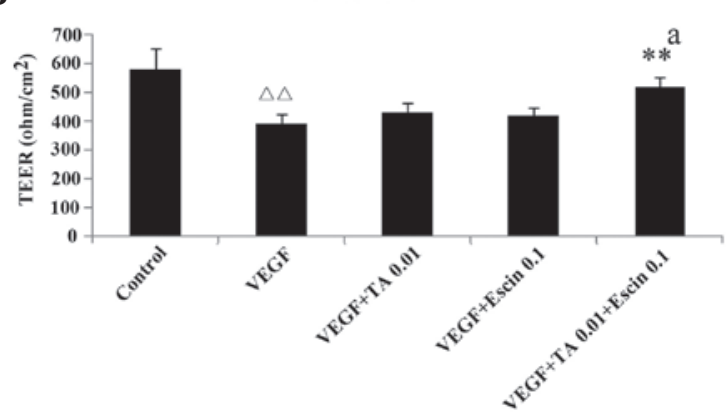

Figure 4. The protective effects of TA combined with escin against blood-retinal barrier damage in (A) HUVECs and (B) retinal pigment epithelial (ARPE-19) cells. Escin $(0.1 \mu \mathrm{g} / \mathrm{ml})$ and TA $(0.01 \mu \mathrm{mol} / \mathrm{L})$ administered separately had no significant impact on the TEER of cellular tight junctions, however, administered together, they significantly increased the TEER of cellular tight junctions in the presence of VEGF $(\mathrm{P}<0.05)$. Data are expressed as the mean \pm standard deviation, $\mathrm{n}=3$ per group. ${ }^{\Delta} \mathrm{P}<0.05$ and ${ }^{\Delta \Delta} \mathrm{P}<0.01$ vs. the control group. ${ }^{* *} \mathrm{P}<0.01$ vs. the VEGF group. ${ }^{\mathrm{a}} \mathrm{E}(\mathrm{da}, \mathrm{db})<\mathrm{E}(\mathrm{da})+\mathrm{E}(\mathrm{db})$ HUVECs, human umbilical vein endothelial cells; TEER, transepithelial electrical resistance; VEGF, vascular endothelial growth factor; TA, triamcinolone acetonide.

Effects of TA combined with escin on the expression levels of occludin and ZO-1 in HUVECs. Compared with the control group, the occludin and ZO-1 protein expression levels in HUVECs treated with VEGF was significantly reduced $(\mathrm{P}<0.05)$. Low concentrations of escin or TA alone did not enhance the occludin and ZO-1 expression levels compared with those observed in the VEGF group. However, when escin and TA were administered together, occludin and ZO-1 expression levels increased significantly compared with those of the control group $(\mathrm{P}<0.05)$ (Fig. 5).

Effects of TA combined with escin on $G C$ receptor expression of HUVECs. Low dose escin or TA alone did not enhance the GC receptor expression compared with the VEGF group. However, when escin and TA were administered together,
GC receptor expression increased significantly $(\mathrm{P}<0.05)$ (Fig. 6).

\section{Discussion}

The BRB is composed of tight and adherent junction complexes. Retinal vascular endothelium and pigment epithelium have well developed tight junctions that confer a high degree of control on solute and fluid permeability, which maintains the neural environment of retina. Intact BRB function is essential for proper vision and its breakdown greatly contributes to the pathology and vision loss in retinal disorders including DR, age-related macular degeneration and uveitis.

TEER measurement is a common method for evaluating the formation of tight junctional complexes. The present study 
A

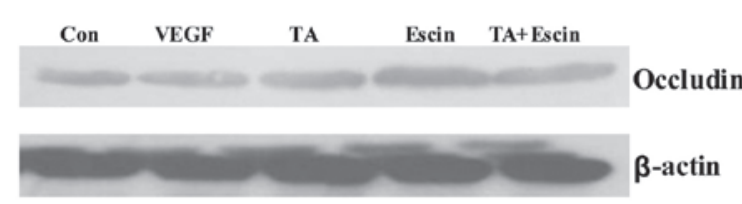

C

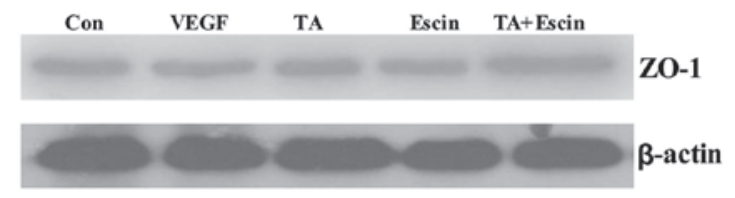

B

D
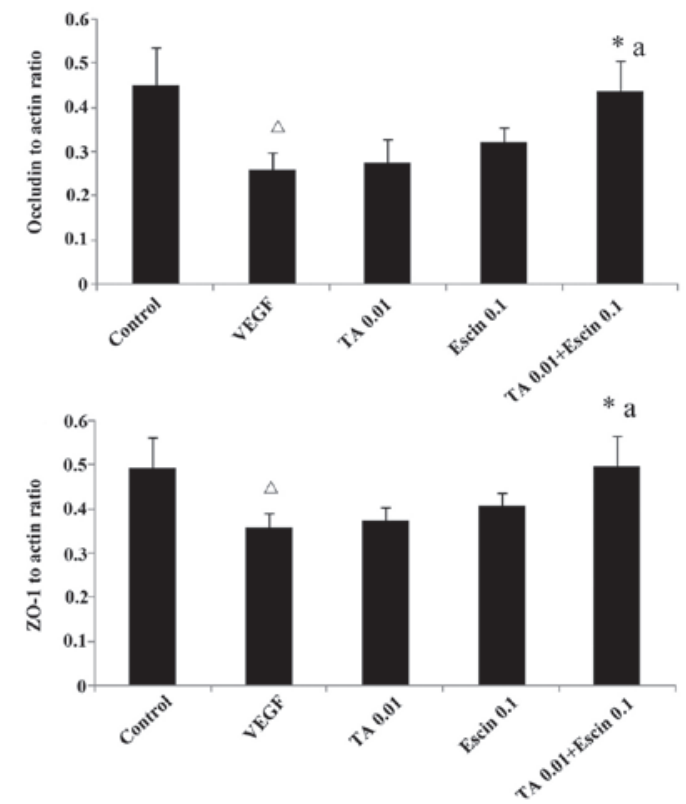

Figure 5. The effects of TA combined with escin on the occludin and ZO-1 expression levels in human umbilical vein endothelial cells. Compared with the control group, the (A and $\mathrm{B}$ ) occludin and (C and D) ZO-1 protein expression levels in the HUVECs treated with VEGF were significantly reduced ( $\mathrm{P}<0.05)$. Low concentrations of escin or TA alone did not enhance the occludin and ZO-1 expression levels compared with those observed in the VEGF group. However, when escin and TA were administered together, occludin and ZO-1 expression levels increased significantly compared with those of the control group $(\mathrm{P}<0.05)$.Data are expressed as the mean \pm standard deviation, $\mathrm{n}=3$ per group. ${ }^{\Delta} \mathrm{P}<0.05$ vs. the control group. ${ }^{*} \mathrm{P}<0.05 \mathrm{vs}$. the $\mathrm{VEGF}$ group; ${ }^{a} \mathrm{E}(\mathrm{da}, \mathrm{db})<\mathrm{E}(\mathrm{da})+$ $\mathrm{E}(\mathrm{db})$. VEGF, vascular endothelial growth factor; TA, triamcinolone acetonide.

A

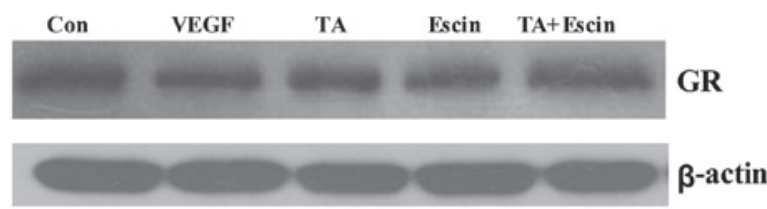

B

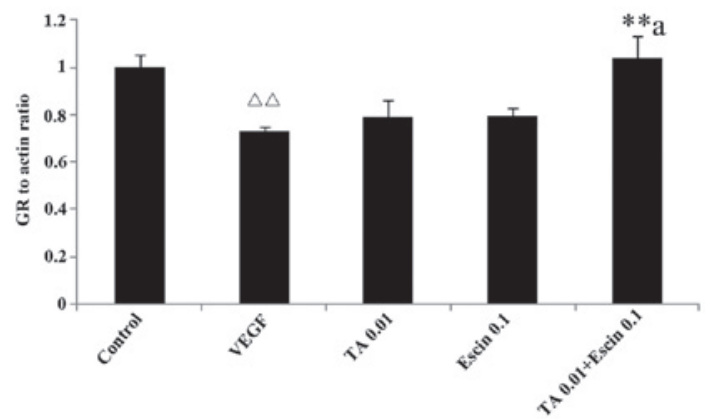

Figure 6. The effects of TA combined with escin on glucocorticoid receptor expression levels in human umbilical vein endothelial cells. (A and B) Low dose escin or TA alone did not enhance the glucocorticoid receptor expression compared with the VEGF group. However, when escin and TA were administered together, glucocorticoid receptor expression increased significantly $(\mathrm{P}<0.05)$. Data are expressed as the mean \pm standard deviation, $\mathrm{n}=3$ per group. ${ }^{\Delta} \mathrm{P}<0.01$ vs. the control group; ${ }^{* *} \mathrm{P}<0.01$ vs. the VEGF group. ${ }^{a} \mathrm{E}(\mathrm{da}, \mathrm{db})<\mathrm{E}(\mathrm{da})+\mathrm{E}(\mathrm{db})$. VEGF, vascular endothelial growth factor; TA, triamcinolone acetonide.

used an in vitro model of BRB based on ARPE-19 cells and HUVECs on permeable transwell inserts. The BRB model established the tightness of the created monolayer as reflected by high TEER and high expression levels of adherens and tight junctional proteins. Occludin and ZO-1 are two important transmembrane proteins in tight junctions that are responsible for forming the permeability barrier (18).

VEGF has an important role in BRB breakdown $(19,20)$. Elevated levels of VEGF can alter the integrity of the BRB and increase the vascular permeability in a number of pathological conditions, including diabetic macular edema $(21,22)$. In the present study, following VEGF treatment, TEER and the expression levels of the tight junctional proteins occludin and ZO-1 were significantly reduced. The levels of TEER and tight junctional proteins in cells treated with escin $(1,10 \mu \mathrm{g} / \mathrm{ml})$ and TA $(0.1,1 \mu \mathrm{mol} / \mathrm{l})$ were significantly increased when compared with those observed in control cells treated VEGF. Separately, escin $(0.1 \mu \mathrm{g} / \mathrm{ml})$ and TA $(0.01 \mu \mathrm{mol} / \mathrm{L})$ had no significant impact on the TEER and cellular tight junctions, however, when administered together they significantly inhibited the reduction of TEER, indicating that escin and TA have synergistic effects which reduce BRB breakdown.

Currently, GCs are the most commonly used medicine for ocular diseases. Several studies have reported on the efficacy and complications associated with intravitreal GC injection for the treatment of diabetic macular edema $(23,24)$. GCs may act by suppressing inflammation and directly affecting the endothelial cells through regulating the phosphorylation, organization, and content of tight junction proteins. The effect of GCs is dependent on the GC receptor as demonstrated by siRNA (25). In the present study, administration of escin and TA together increased GC receptor expression significantly, which may be 
one of the mechanisms by which escin protects against the BRB breakdown.

In conclusion, escin and GCs have synergistic protective effects on BRB breakdown, and the molecular mechanism is related to the upregulation of occludin and ZO-1. Administration of escin allows for the reduction of the dose of GCs for treatment of macular edema. The combination of escin with GCs indicates a beneficial method for the treatment of BRB breakdown.

\section{Acknowledgements}

This study was supported by the Project of Yantai Science and Technology Development Program (no. 2013WS205).

\section{References}

1. Sander B, Larsen M, Moldow B and Lund-Andersen H: Diabetic macular edema: passive and active transport of fluorescein through the blood-retina barrier. Invest Ophthalmol Vis Sci 42 : 433-438, 2001

2. Qaum T, Xu Q, Joussen AM, et al: VEGF-initiated blood-retinal barrier breakdown in early diabetes. Invest Ophthalmol Vis Sci 42: 2408-2413, 2001.

3. Mathews MK, Merges C, McLeod DS and Lutty GA: Vascular endothelial growth factor and vascular permeability changes in human diabetic retinopathy. Invest Ophthalmol Vis Sci 38: 2729-2741, 1997

4. Kernt M, Thiele S, Liegl RG, et al: Axitinib modulates hypoxia-induced blood-retina barrier permeability and expression of growth factors. Growth Factors 30: 49-61, 2012.

5. Wilson CA, Berkowitz BA, Sato Y, Ando N, Handa JT and de Juan E Jr: Treatment with intravitreal steroid reduces blood-retinal barrier breakdown due to retinal photocoagulation. Arch Ophthalmol 110: 1155-1159, 1992

6. McAllister IL, Vijayasekaran S, Chen SD and Yu DY: Effect of triamcinolone acetonide on vascular endothelial growth factor andoccludin levels in branch retinal vein occlusion. Am J Ophthalmol 147: 838-846, 2009.

7. Jonas JB, Kreissig I and Degenring R: Intraocular pressure after intravitreal injection of triamcinolone acetonide. $\mathrm{Br}$ J Ophthalmol 87: 24-27, 2003.

8. Jonas JB, Degenring R, Vossmerbauemer U and Kamppeter B: Frequency of cataract surgery after intravitreal injection of high-dosage triamcinolone acetonide. Eur J Ophthalmol 15: 462-464, 2005.

9. Zhang L, Fu F, Zhang X, Zhu M, Wang T and Fan H: Escin attenuates cognitive deficits and hippocampal injury after transient global cerebral ischemia in mice via regulating certain inflammatory genes. Neurochem Int 57: 119-127, 2010.
10. Xin W, Zhang L, Fan H, Jiang N, Wang T and Fu F: Escin attenuates acute lung injury induced by endotoxin in mice. Eur J Pharm Sci 42: 73-80, 2011.

11. Wang T, Fu F, Zhang L, Han B, Zhu M and Zhang X: Effects of escin on acute inflammation and the immune system in mice. Pharmacol Rep 61: 697-704, 2009.

12. Zhang L, Wang H, Fan H, et al: The potent anti-inflammatory agent escin does not increase corticosterone secretion and immune cell apoptosis in mice. Fitoterapia 82: 861-867, 2011.

13. Xin W, Zhang L, Sun F, et al: Escin exerts synergistic anti-inflammatory effects with low doses of glucocorticoids in vivo and in vitro. Phytomedicine 18: 272-277, 2011.

14. Gong YY, Yu SQ, Wang H, et al: Clinical therapy of retinal vein occlusion with aescuven forte. Chin J New Drugs Clin Rem 12: 965-968, 2005.

15. Wang W, Gong Y, Wang $\mathrm{H}$, et al: Aescuven forte in treating central serous chorioretinopathy. Chin J New Drugs Clin Rem 12: 961-964, 2005.

16. Yuan YL and Wu LL: Clinical observation of the central serous chorioretinopathy treated by aescinate sodium tablets combined with argon laser. Guiding Journal of TCM and Pharmacology 15: 58-59, 2009 (In Chinese).

17. Berenbaum MC: What is synergy? Pharmacol Rev; 41: 93-141, 1989.

18. Furuse M, Hirase T, Itoh M, et al: Occludin: a novel integral membrane protein localizing at tight junctions. J Cell Biol 123: 1777-1788, 1993.

19. Shibuya M: Vascular endothelial growth factor receptor(VEGFR-1/Flt-1): a dual regulator for angiogenesis. Angiogenesis 9: 225-230, 2006.

20. Duh EJ, Yang HS, Suzuma I, et al: Pigment epithelium-derived factor suppresses ischemia-induced retinal neovascularization and VEGF-induced migration and growth. Invest Ophthalmol Vis Sci 43: 821-829, 2002.

21. Esser S, Wolburg K, Wolburg H, et al: Vascular endothelial growth factor induces endothelial fenestrations in vitro. J Cell Biol 140: 947-959, 1998.

22. Antonetti DA, Barber AJ, Hollinger LA, Wolpert EB and Gardner TW: Vascular endothelial growth factor induces rapid phosphorylation of tight junction proteins occludin and zonula occluden-1. A potential mechanism for vascular permeability in diabetic retinopathy and tumors. J Biol Chem 274: 23463-23467, 1999.

23. Stewart MW: Corticosteroid use for diabetic macular edema: old fad or new trend? Curr Diab Rep 12: 364-375, 2012.

24. Liu L, Wu X, Geng J, Yuan Z and Chen L: IVTA as adjunctive treatment to PRP and MPC for PDR and macular edema: a meta-analysis. PLoS One 7: e44683, 2012.

25. Felinski EA, Cox AE, Phillips BE and Antonetti DA: Glucocorticoids induce transactivation of tight junction genes occludin and claudin-5 in retinal endothelial cells via a novel cis-element. Exp Eye Res 86: 867-878, 2008. 